\title{
Relações de poder entre gêneros no ambiente organizacional: uma análise da representação feminina nas empresas de Tecnologia da Informação (TI) de Porto Alegre - RS
}

Power relations between gender with the organizational environment: an analysis of fe-
male representation in information technology companies (IT) in Porto Alegre - RS

Francielle Piffero Camargo

Especialista em Administração

Pontifícia Universidade Católica do Rio Grande do Sul

fran.piffero@hotmail.com

Cláudia Lehnemann Tannhauser

Doutora em Ciências da Saúde

Pontifícia Universidade Católica do Rio Grande do Sul

claudia.tcamed@terra.com.br

Uiliam Hahn Biegelmeyer

Doutora em Administração

Pontifícia Universidade Católica do Rio Grande do Sul

uiliam.hb@terra.com.br

Maria Emilia Camargo

Doutora em Engenharia de Produção

Universidade de Caxias do Sul

mariaemiliappga@gmail.com

Flávia Camargo Bernardi

Mestra em Administração

Universidade de Caxias do Sul

flavia.bernardi@mkfsolucoes.com.br

Tânia Craco

Doutora em Administração

Instituto Federal do Rio Grande do Sul

tcraco@yahoo.com.br

\section{Resumo}

Este artigo traz o resultado da análise das relações de poder entre gêneros e a representatividade feminina das empresas de tecnologia da informação (TI) de Porto Alegre - RS. Apesar de certos avanços de equidade entre gêneros, a desigualdade ainda está presente nas organizações. $O$ estudo analisou o motivo que impede o ingresso e a permanência das mulheres na Tl e também investigou sua atual inserção, atuação e relações de poder no mercado de tecnologia da informação. Na pesquisa qualitativa exploratória, foram entrevistadas 10 mulheres que trabalham na área de TI. Como instrumento de coleta de dados, foi utilizada a entrevista com roteiro de perguntas semiestruturada. A 
análise dos dados foi feita mediante análise de conteúdo. Os resultados apontaram para o fato de que ainda existem diferenças de gênero significativas na área de $\mathrm{TI}$, seja no ambiente acadêmico, que leva à desistência da maioria das mulheres, quanto no ambiente organizacional e nas práticas e relações do dia a dia, que colocam a mulher em uma situação subalterna e discriminatória.

\title{
Palavras-chave
}

Equidade de gênero. Relações de poder. Tecnologia da informação e comunicação. Trabalho da mulher. Empoderamento.

\begin{abstract}
This article presents the results of the analysis of power relations between genders as well representation of women in the information technology (IT) companies in Porto Alegre - RS. Despite some advances in gender equity, inequality is still present in many organizations. The study analyzed the reason that prevents the entry and staying power of women in the IT. Also the study investigated the current presence and progress of women in this area. In addition, the study investigated the gender power relations in the information technology market. In the exploratory qualitative research, ten (10) women working in the field of IT were interviewed. Semi-structured interviews were used as a data collection tool. The data analysis was based on a content analysis method. The result of the study points to the fact that there are still significant gender differences in IT area, both in the academic environment and in the organizational scope. The daily practice of segregation in relations place women in subordinate and discriminatory situations which leads most women to give up to working in this area.
\end{abstract}

\section{Keywords}

Gender equity. Power relations. Technology of Information and Communication. Woman work. Empowerment.

\section{INTRODUÇÃO}

O crescimento da participação feminina no mercado de trabalho vem sofrendo mudanças significativas, visto que o crescimento do público feminino já supera o masculino. Segundo o Ministério do Trabalho e Emprego, na última Relação Anual de Informações Sociais, "em um recorte por gênero, os dados evidenciam que, em 2018, o nível de emprego da mão de obra feminina cresceu $3,91 \%$, ante um aumento de $2,57 \%$ para os homens, uma diferença de 1,34 pontos percentuais."

$O$ ingresso acentuado das mulheres no trabalho continua em constante evolução, conforme revela o estudo da RAIS 2018: "A continuidade no processo de elevação da participação das mulheres no mercado trabalho formal passou de 42,47\% em 2017 para 42,79\% em 2018." Também, ao longo do tempo, a inserção feminina no mercado de trabalho vem resultando em transformações marcantes. Esse processo se consolida a cada dia, deixando de ser um movimento apenas temporário, tornando o processo de fenômeno social contínuo (GARCIA; CONFORTO, 2012).

A história da mulher no mercado de trabalho formal começou, de fato, com as I e II Guerras Mundiais (1914-1918 e 1939-1945, respectivamente). Devido à ida dos homens para as Guerras, as mulheres assumiram posição de comando e sustento de suas casas. Após o fim da Guerra, com o baixo número de sobreviventes e homens possibilitados de retornar ao trabalho, a consolidação do sistema capitalista, o desenvolvimento tecnológico intenso e o movimento feminista no século XX, houve mudanças de ordem social, econômica e política que resultaram em uma nova composição no mercado de trabalho: a mão de obra feminina. 
Foi por meio do trabalho que a mulher diminuiu a distância que a separava do homem, visto que somente o trabalho poderia garantir-Ihe uma emancipação (BEAUVOIR, 1975).

É grande o número de mulheres que deixaram para trás barreiras seculares e passaram a contribuir para a economia nacional. Desde as primeiras décadas do século XX, tornou-se visível a atuação feminina em diversos segmentos do mercado de trabalho (SIMÕES, 2012).

Contudo, a equidade entre gêneros no mercado de trabalho ainda está em processo de construção, pois mesmo com todas essas mudanças até o momento, a mulher ainda se encontra em posição menos favorecida em relação aos homens devido às desvantagens que encontra durante sua carreira, principalmente no que se refere à desigualdade salarial. Segundo dados da pesquisa do World Economic Forum (2011), "O Brasil é um dos piores países do mundo nesta questão salarial. As mulheres chegam a ganhar metade dos homens em alguns casos para trabalhar na mesma função." O ranking mostra o Brasil como o 82 país onde há mais desigualdade entre homens e mulheres.

Coelho (2014) diz que, em um mundo marcado por tradições patriarcais, as mulheres têm seus direitos civis e humanos constantemente ameaçados. O fortalecimento e empoderamento das mulheres ocorrem pelo reconhecimento dos seus direitos e da visibilidade das violências às quais estão sujeitas, com o consequente enfrentamento dessa violação dos direitos humanos.

A dificuldade de ocupação em cargos considerados masculinos também ocorre, uma vez que a mulher nesta posição enfrenta dificuldade em obter respeito e passa a disputar poder com homens neste mesmo cargo. "As organizações são geridas por homens há séculos e, com a inserção da mulher no mercado de trabalho, estes temem perder os privilégios que os fazem sentir-se superiores a elas." (SILVA, 2010).

No espaço organizacional, têm-se indivíduos inseridos dentro de um contexto sóciohistórico e cultural e, dentro deste espaço, pode-se observar que as relações de poder entre gêneros se interpõem. Costa et al. (2012) explicam que se gênero é a primeira maneira de significar as relações de poder, torna-se primordial compreender como estas se propagam socialmente e fazem parte da construção social do masculino e feminino.

Dessa forma, pode-se perceber que em qualquer grupo social há uma dominação do gênero masculino em relação ao feminino e, nesse caso, analisando os grupos organizacionais, nota-se que em determinadas áreas há predominantemente uma dominação do gênero masculino. Segundo os dados divulgados pelo Instituto de Estudos e Pesquisas Educacionais Anísio Teixeira (INEP), o resultado do censo de educação superior em 2016 revela a representatividade dos graduandos por gênero e mostra a importância do enfrentamento da segregação nas escolhas de carreira.

As mulheres estão quase que na totalidade matriculadas em cursos de Ciências Humanas, Sociais e Saúde, e os homens estão, em sua maioria, nas áreas de Ciências Exatas e Tecnologias. Para Barbosa, Carvalho e Fernandes (2013, p. 219-220) "[...] a presença das mulheres na educação superior se distribui de forma segregada, existindo espaços marcadamente femininos e masculinos."

Sabe-se, através de dados estatísticos, que o número de mulheres que integram a área de tecnologia é menor que a representação masculina e pergunta-se o porquê. Segundo uma pesquisa realizada na internet pela Application Program Interface (APINFO, 2012), a participação de mulheres no mercado de informática representa apenas $13 \%$. Embora o ramo de Tecnologia da Informação (TI) seja considerado inovador e as empresas desta área sejam consideradas modernas, analisou-se o porquê do pouco ingresso de mulheres na área. 
Olinto (2011) aponta que fazer carreira nas áreas de TI é uma escolha marcante entre os homens. Questiona-se, então, como tem se dado a atuação das mulheres nas áreas da TI atualmente. Sendo assim pergunta-se: "'Qual o motivo do pouco ingresso e da desistência das mulheres em carreiras na área de TI?"

Diante do exposto, o presente estudo teve como objetivo geral analisar qual o motivo do pouco ingresso e da desistência das mulheres em carreiras na área de TI. Apresentam-se como objetivos secundários analisar a atual inserção, a atuação e as relações de poder entre gêneros neste espaço.

Para atingir os objetivos propostos, o trabalho está estruturado com a presente introdução, revisão da literatura, método de pesquisa, apresentação e análise dos resultados, considerações finais e, ao fim, com as referências utilizadas.

\section{A PARTICIPAÇÃO DA MULHER NO MERCADO DE TRABALHO}

A Constituição Federal de 1934, Artigo 113, inciso 1, garantiu que "[...] todos são iguais perante a lei." Rocha et al. (2013) especificam que, com a Constituição de 1934, houve um avanço significativo no campo trabalhista, inserindo, em suas leis, a jornada diária de oito horas, o nivelamento de salários, o descanso semanal, as férias remuneradas, saláriomaternidade, a licença maternidade, a proibição de mulheres em trabalhos insalubres, e a assistência médica e sanitária as gestantes. Além de reorganização das normas de proteção à maternidade nos âmbitos trabalhista e previdenciário (art. 392) e seguintes, assim como a da Consolidação das Leis do Trabalho (CLT), com acréscimos da Lei 9799/99 e Lei 8213/91 e instituição de normas de combate à discriminação e meios que atribuíam igualdade entre os sexos (Lei 9029/95 e 9799/99).

O movimento feminista, desde o século $X X$, quando começou a adquirir características de ação política, também vem promovendo ações e debates acerca dos direitos das muIheres e tentando colocar em prática essas obrigatoriedades.

O foco acadêmico sobre relações de gênero remonta aos estudos feministas da década de 1960, que procuraram denunciar a segregação política, econômica e social em relação à mulher e, por meio de suas lutas, chamou a atenção para as desigualdades das mulheres, aprofundando suas reflexões, possibilitando o aparecimento de trabalhos sobre relações de gênero e mulher, desconstruindo argumentos historicamente tomados como naturais. $\mathrm{O}$ principal deles, firmado na ideia da diferenciação biológica e sexual de homens e mulheres como justificadora das desigualdades sociais, foi, desde o início, contestado pelos estudos feministas, os quais procuraram demonstrar que as identidades do masculino e do feminino constroem-se cotidianamente na esfera do social, não pelas características sexuais, mas sim pela forma como essas características são valorizadas e representadas em diferentes contextos históricos (SABOYA, 2012).

Ferreira et al. (2012) ressaltam o projeto de lei 130/2011 da Câmara dos Deputados, o qual prevê multa para as empresas que diferenciarem o salário entre homens e mulheres que desempenham a mesma função. Tal emenda tem o intuito de corrigir a desigualdade de remuneração entre os sexos. Em contrapartida, sabe-se que há escape dessa lei, uma vez que os dados de pesquisas já realizadas e mencionadas neste artigo demonstram que, em muitos lugares, há disparidade de salários entre os gêneros.

Quanto à representação em cargos de poder no ambiente corporativo e a ascensão profissional, deve-se analisar o fenômeno chamado "teto de vidro" (glass-ceiling em inglês), mecanismo que faz com que as mulheres não avancem na sua profissão. Esse fenômeno 
caracteriza-se pela menor velocidade com que as mulheres progridem na carreira, o que resulta em sua sub-representação nos cargos de comando das empresas e, consequentemente, nas altas esferas do poder, do prestígio e das remunerações. Isso é observado mesmo quando as mulheres possuem características produtivas idênticas ou superiores às do gênero masculino (VAZ, 2013).

A existência de barreiras ao acesso a maiores níveis de hierarquia e comando compromete, geralmente, as mulheres na construção da sua carreira. Olinto (2011) diz que o "teto de vidro" é um tipo de segregação que faz com que as mulheres não progridam em seus ambientes de trabalho e mantenham posições mais subordinadas do que os homens, principalmente nas carreiras de Ciência e Tecnologia. Conseguir a redução dessa disparidade econômica, social e de dimensão de gênero é importante para o empoderamento da mulher e da sua autonomia econômica.

\subsection{Diversidade de mão de obra nas organizações e divisão sexual do trabalho}

A diversidade relaciona as características observáveis, que são aquelas reconhecidas como cor, gênero, etnia, idade e características não observáveis como a personalidade, religião, entre outras. (SORANZ, 2010). Praticar diversidade implica muitas vezes em mudar comportamentos, os quais muitas vezes são viscerais. Mudanças desse tipo requerem uma opção explícita da direção da organização para que se tenha êxito. "A questão da diversidade tem se consolidado na pauta empresarial em todo o mundo, principalmente em razão das diferenças na força de trabalho." (ALVES; GALEÃO-SILVA, 2004, p. 20).

Desenvolver políticas internas que possam garantir a difusão de uma cultura cidadã e igualitária é importante não apenas no sentido de consolidar uma imagem positiva da empresa no mercado, mas também para proporcionar um ambiente corporativo harmonioso e que respeite as diferenças para seus próprios funcionários (ALENCAR, 2015).

Estima-se que, em 2014, de cada 100 mulheres em idade ativa, 51 estavam no mercado de trabalho. Comparada à inserção dos homens, para os quais de cada 100 em idade ativa havia 72 ocupados, ainda existe uma grande diferença em relação à participação das mulheres, mas essa diferença vem diminuindo quando se fala de representatividade em números.

Existem também desigualdades quanto à divisão de gênero do trabalho, uma vez que há áreas já definidas para homem e para mulher. Conforme Lúcio e Garcia (2016), essa desigualdade ocorre porque as mulheres ocupam postos de trabalho que pagam menores salários, alguns tipicamente femininos; porque há empregos tipicamente masculinos que pagam melhor e aos quais as mulheres não têm acesso; porque elas têm maior dificuldade para progredirem aos postos de direção ou aos melhores empregos, por diversos fatores.

Essa concepção tradicional tem sido confrontada com as intensas transformações que o mundo do trabalho tem presenciado, sobretudo a partir das últimas décadas do século XX. Um exemplo é a crescente participação de mulheres em diferentes ocupações, até mesmo naquelas que anteriormente estiveram restritas aos homens, como a Engenharia e a Medicina. Contudo, ainda se conservam algumas permanências (DANIEL, 2011).

A literatura mostra que, em ramos predominantemente masculinos, a mão de obra feminina enfrenta dificuldades que não são compartilhadas pelos homens. Daniel (2011) diz que a entrada de mulheres em profissões, cargos e espaços de trabalho, que anteriormente eram ocupados apenas por homens abre a possibilidade para que os indivíduos envolvidos 
se questionem sobre a validade de um modelo de divisão sexual do trabalho calcado em habilidades ditas naturais.

Ramos (2011) cita que entre as diretrizes da Política Nacional para Mulheres está o reconhecimento da responsabilidade do Estado na implementação de políticas que incidam na divisão social e sexual do trabalho; que priorizem a promoção de relações de trabalho não discriminatórias e que assegurem a equidade entre homens e mulheres ao acesso a cargos de direção. E ainda diz que, notavelmente, as mulheres ocupam posição inferior aos homens no mercado de trabalho.

\subsection{Diversidade de mão de obra na área de TI}

O desenvolvimento de sistemas informatizados desde a especificação de requisitos até os testes de implantação, bem como as tecnologias de comutação, transmissão, recepção de dados, podem constituir-se em especificidades desse eixo (REZENDE, 2014). Segundo o Ministério da Educação e Cultura (BRASIL, 2010), os cursos reconhecidos nas áreas de TI são: Análise e Desenvolvimento de Sistemas; Banco de Dados; Geoprocessamento; Gestão da Tecnologia da Informação; Gestão de Telecomunicações; Jogos Digitais; Redes de Computadores; Redes de Telecomunicações; Segurança da Informação; Sistemas de Telecomunicações; Sistemas para Internet e Telemática.

No entanto, a realidade atual é que o mercado de tecnologia ainda é um setor dominado pelos homens, o que está mudando, mas longe da disparidade ser ideal (FERREIRA et al., 2012)

Nem sempre o mercado de TI foi dominado exclusivamente por homens. Para que possa se afirmar isso, deve-se analisar como se deu o início da $\mathrm{TI}$ no Brasil. Ferreira et al. (2012) expõem que, em 1960, a Pontifícia Universidade Católica do Rio de Janeiro (PUC-RIO) foi a primeira universidade do país a criar um Departamento de Informática. Em 1968, a Universidade Estadual de Campinas (UNICAMP) lançou o Bacharelado em Ciência da Computação, primeiro curso de nível superior relacionado à tecnologia no Brasil. O Instituto de Matemática e Estatística da Universidade de São Paulo (USP) abriu vagas para o mesmo curso em 1974. Quando as turmas de cursos com foco em tecnologia começaram a ser criadas em nosso país, a maioria dos estudantes dessas fileiras era mulheres. Assim sendo, boa parte dos pioneiros em computação no Brasil eram mulheres. Mas essa situação se inverteu drasticamente em virtude de que as mulheres estudavam tecnologia quando a profissão era nova no País e ainda não gerava dinheiro. Mais tarde, quando a formação nessa área se tornou mais valorizada, os homens passaram a buscar esses cursos.

No entanto, sabe-se que $79 \%$ das mulheres abandonam o curso no primeiro ano, o que pode demonstrar que o problema talvez esteja no curso, e não nas mulheres. Isto é, não na metodologia, mas sim no ambiente encontrado pelas mulheres que se aventuram em uma carreira preponderantemente masculina: é ridiculamente fácil dizer que as mulheres não se esforçam o suficiente ou não têm pendor para as ciências exatas quando se escolhe esquecer que ser minoria em qualquer lugar é uma tarefa que pode variar do difícil até o debilitante. Acreditar que os $79 \%$ de mulheres desistem dos cursos de TI por desilusão, preguiça e incompetência e que tudo isso não tem relação nenhuma com o ambiente é de uma inocência quase que enternecedora (FERREIRA et al., 2012).

Mesmo com o aumento da presença de mulheres inseridas no Ensino Superior (INEP, 2013), a preferência feminina continuou sendo nos campos tradicionalmente considerados para o seu gênero. Isso mostra que as diferenças às quais as mulheres foram submetidas 
historicamente ainda influenciam a formação do vínculo com o conhecimento (LIMA, 2013). Em outubro de 2013, o Ministério de Ciência, Tecnologia e Inovação (MCTI), o Conselho Nacional de Desenvolvimento Científico e Tecnológico (CNPq), a Secretaria de Políticas para as Mulheres da Presidência da República (SPM-PR) e a Petrobras lançaram uma chamada pública intitulada "Meninas e Jovens fazendo Ciências Exatas, Engenharias e Computação" (№ 18/2013 MCTI/CNPq/SPM-PR/Petrobras), com o objetivo de ampliar o número de estudantes do sexo feminino nas carreiras de Ciências Exatas, Engenharias e Computação, através do fomento de projetos que pudessem contribuir de forma significativa para o desenvolvimento científico e tecnológico e para a inovação no País. No Brasil, essa iniciativa importante e de vanguarda intenciona reverter a pequena participação das mulheres nessas carreiras, um problema mundial que já vem sendo enfrentado com políticas de "discriminação" positiva em alguns países. (QUEIROZ; CARVALHO; MOREIRA, 2014).

Observa-se que a área de TI continua com baixa representatividade delas. Lima (2013) reafirma ao dizer que a preferência da mulher continuou sendo nas áreas tradicionalmente consideradas femininas. Isso mostra que as diferenças de gêneros às quais as muIheres foram submetidas historicamente ainda influenciam a formação do vínculo com o conhecimento.

Ainda segundo dados do INEP nos anos de 2012 e 2013, o número de mulheres que ingressaram, matricularam e concluíram a educação superior no Brasil se mostrou maior do que o número de homens. Porém, é notável que a preferência dos cursos escolhidos pelo público feminino fica restrita às áreas de humanas e saúde. Já entre o público masculino, os dados mostram que as áreas de maior inserção estão ligadas às exatas, como as engenharias e os cursos relacionados à tecnologia (MOREIRA; MATTOS; REIS, 2014), conforme mostra a Figura 1. Entre os cursos escolhidos, foi observado que, no curso de Ciência da Computação, a participação dos homens chega a 79,9\%, enquanto a participação das mulheres é de apenas $20,1 \%$. Além de ser um número de mulheres bastante pequeno, em meados dos anos 1990, esses números eram ainda menores, chegando em $5 \%$, segundo dados da Sociedade Brasileira da Computação.

Figura 1 - Ingresso, matrícula e conclusão no ano de 2013

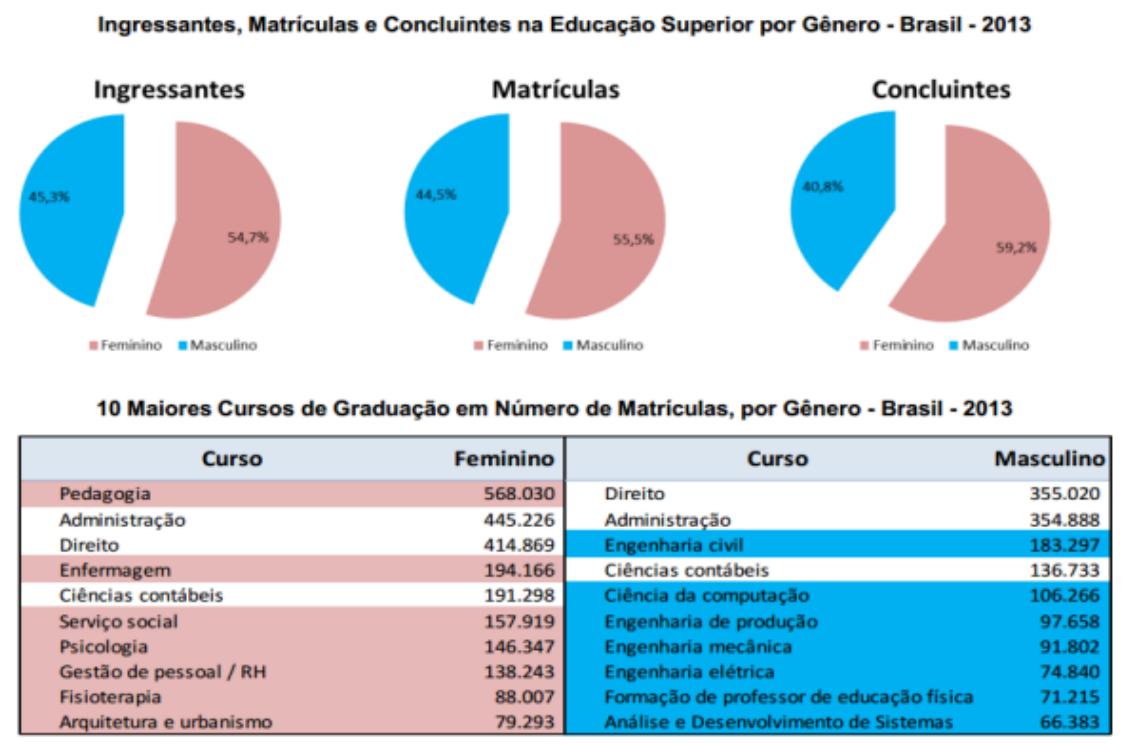

Fonte: MEC/INEP (INEP, 2013). 
Observa-se o pouco ingresso e número baixo de mulheres concluintes na graduação em cursos de TI. Um dos fatores para essa realidade é a dificuldade que enfrentam já em sala de aula. Pinto, Carvalho e Rabay (2014) questionam se existem desestímulos e obstáculos explícitos e sutis na cultura, nas práticas e relações escolares, acadêmicas, profissionais e interpessoais, nos currículos e nas práticas pedagógicas. Saboya e Carvalho (2012) identificam diferentes formas de hostilização colocadas em prática pelos colegas em relação a elas, por isso criaram táticas variadas para se manter e progredir nos cursos.

A principal ação a ser feita é formar professores/as com a compreensão da necessidade de eliminar os estereótipos de gênero nas relações didático-pedagógicas que levam a maioria das estudantes a escolherem cursos superiores tipicamente femininos e sensibilizar profissionais da educação sobre a naturalização das relações sociais para problematizar e modificar as relações de poder que classificam homens e mulheres de forma desigual e hierárquica (QUEIROZ; CARVALHO; MOREIRA, 2014). Embora a problemática da subrepresentação feminina na Ciência e Tecnologia seja visível, ela não tem sido problematizada nas instituições de educação superior (COOPER et al., 2010).

As constatações apresentadas sugerem algumas questões: as mulheres que resolveram enfrentar as barreiras e decidiram seguir na carreira de tecnologia enfrentam dificuldades nas empresas? Elas também enfrentam iniquidades em seu progresso de carreira quando passam a disputar cargos de poder com homens neste ambiente de trabalho?

Sobre a dinâmica de gêneros nos altos postos executivos, Lima (2013) diz que ainda há preconceitos sobre a capacidade de liderança da mulher. Tal fator, que influencia também a possibilidade de maior conquista em cargos de poder nas empresas, uma vez que elas enfrentam outros desafios ligados a um ambiente ainda masculino e passam a disputar cargos com os homens (estes já afirmados socialmente como mais habilidoso para área de exatas), começa outra barreira, conhecida como "teto de vidro" na literatura. Almeida (2012) explica que o fenômeno do teto de vidro, apesar de sutil, é suficientemente forte para impossibilitar a ascensão de mulheres a níveis mais altos no organograma organizacional.

A discussão sobre o efeito teto de vidro iniciou-se na década de 1980 nos Estados Unidos e incentivou a criação de uma comissão, criada em 1991, pela Secretaria do Trabalho nos Estados Unidos. Naquela ocasião, o governo americano buscava uma forma de regulamentar o mercado com a finalidade de reduzir barreiras que impedissem as mulheres de aproveitarem oportunidades de carreira e de promoção da mesma forma que os homens (MADALOZZO, 2011).

Madalozzo (2011) traz que, apesar do crescente número de mulheres no mercado de trabalho, ainda persiste a discussão a respeito da baixa entrada das mulheres em cargos elevados nas empresas em que trabalham. Além disso, outra barreira no crescimento da carreira das mulheres é a dupla jornada de trabalho e a conciliação com a vida pessoal.

Devido à necessidade de reter os bons profissionais e a preocupação das empresas em proporcionar um ambiente de trabalho mais diversificado, as mulheres competem em pé de igualdade com os homens no momento da contratação. Porém, por volta dos 35 anos, elas começam a deixar as organizações. Os principais motivos para essa evasão são a culpa de passar pouco tempo com o filho, a inflexibilidade das companhias com relação à jornada de trabalho e a falta de perspectiva de crescimento (FRANÇA, 2011). 


\subsection{Pró-equidade de gênero nas organizações}

No Brasil, há empresas que pregam a prática de igualdade de poder entre gêneros. $\mathrm{O}$ Selo de Qualidade Pró-Equidade de Gênero nas Organizações faz parte das iniciativas idealizadas em prol da busca de igualdade de oportunidades no mundo do trabalho. O selo faz parte do Programa Pró-Equidade de Gênero, que tem por finalidade o desenvolvimento de concepções e procedimentos na gestão de pessoas e na cultura organizacional da empresa para alcançar a equidade de gênero no mundo do trabalho.

O Programa é uma iniciativa do Governo Federal que, por meio da Secretaria Especial de Políticas para as Mulheres da Presidência da República (SPM/PR) e com base no Plano Nacional de Políticas para as Mulheres, reafirma os compromissos de promoção da igualdade entre mulheres e homens inscrita na Constituição Federal de 1988. O programa, que está em sua 6a edição, conta, também, com a parceria do Fundo de Desenvolvimento das Nações Unidas para a Mulher (UNIFEM) e da Organização Internacional do Trabalho (OIT) As organizações participantes que se destacarem na proposta e implementação de iniciativas inovadoras receberão o Selo Pró-Equidade de Gênero - um instrumento de progresso que evidenciará o compromisso com a equidade de gênero e que há promoção da cidadania e há difusão de práticas exemplares entre as diferentes organizações (ALMEIDA, 2012).

Pequenas, médias e grandes empresas que pregam por boas práticas e que desejam estimular a boa prática do tratamento entre gêneros sem abusos de poder, que almejam maior produtividade e satisfação de seus funcionários e funcionárias, melhoria do clima organizacional e fortalecimento da imagem institucional devem participar do Prêmio WEPs (PRÊMIO WEPS BRASIL, 2016).

\section{MÉTODO DE PESQUISA}

A pesquisa científica é uma investigação metódica acerca de um assunto determinado para esclarecer aspectos do objetivo em estudo. Possibilita uma aproximação e um entendimento da realidade a investigar, sendo um processo permanentemente inacabado. Processa-se por meio de aproximações sucessivas da realidade, fornecendo subsídios para uma intervenção no real (BASTOS; KELLER, 2000). Pesquisa científica seria, portanto, a realização concreta de uma investigação planejada e desenvolvida de acordo com as normas consagradas pela metodologia científica, a qual é entendida como um conjunto de etapas ordenadamente dispostas que você deve vencer na investigação de um fenômeno (MORESI, 2003).

Nesta seção, será descrito o método de pesquisa empregado. Será abordado o delineamento da pesquisa, a população-alvo da pesquisa, o instrumento e a aplicação da coleta e as técnicas de análise dos dados. $O$ estudo tem o objetivo de estimar a diferença da existência entre homens e mulheres e suas relações de poder na área de $\mathrm{TI}$.

Com a intenção de analisar as relações de poder entre gêneros nas organizações de TI, neste trabalho foi realizada uma pesquisa de caráter qualitativo exploratório. Para tanto, foi realizada uma entrevista com um roteiro de perguntas semiestruturada.

Segundo Godoy (1995), os estudos qualitativos têm como preocupação determinante o estudo e a análise através de experiência e observação em seu ambiente natural. Nessa abordagem, valoriza-se o contato direto e prolongado do pesquisador com o ambiente e a situação que está sendo estudada. Já para Minayo (1994), a pesquisa qualitativa responde a questões muito particulares. Ela se preocupa com um nível de realidade que não pode ser 
quantificado. Ou seja, ela trabalha com o universo de significados, motivos, aspirações, crenças, valores e atitudes, o que corresponde a um espaço mais profundo, a partir dos quais as ações, as estruturas e as relações se tornam significativas.

Sendo este estudo qualitativo exploratório, para Cervo, Silva e Bervian (2006), a pesquisa exploratória estabelece critérios, métodos e técnicas para a elaboração de uma pesquisa a fim de gerar informações sobre o objeto desta e orientar a formulação de hipóteses. Para Gonçalves (2014), a pesquisa exploratória visa à descoberta, ao achado, à elucidação de fenômenos ou à explicação daqueles que não eram aceitos apesar de evidentes.

Neste trabalho, foi realizada uma pesquisa qualitativa exploratória com 10 mulheres que trabalham na área de $\mathrm{Tl}$ em Porto Alegre, em uma amostra intencional na qual as colaboradoras responderam a entrevista com um roteiro de perguntas semiestruturado.

Para a coleta de dados, foi elaborado um roteiro de entrevista, com perguntas baseadas nas autoras Ferreira et al. (2012) e Regina Madalozzo (2011). Foram elaboradas 13 perguntas abertas, as quais estimularam as respondentes a dissertar seus argumentos com base em suas experiências na área investigada. O questionário foi estruturado, na primeira parte, com informações de caracterização do respondente. Para Marconi e Lakatos (2002), na amostra intencional, uma vez aceita as limitações da técnica, há impossibilidade de generalização dos resultados do inquérito à população, tendo sua validade dentro de um contexto específico.

A pesquisa foi realizada presencialmente e gravada. O tempo médio das entrevistas foi de 12 minutos. Os locais de realização das pesquisas foram no Campus da PUCRS, no Tecnopuc, em Cafés e em casa.

Conforme Marconi e Lakatos (2002), depois dos dados manipulados e obtidos os resultados, o passo seguinte é sua análise e interpretação. Os dados nos proporcionam respostas às investigações. Em função dos resultados serem qualitativos, optou-se, como análise dos dados, a análise de conteúdo. Para Bardin (2009), a análise de conteúdo é um conjunto de instrumentos metodológicos que se aperfeiçoa constantemente e que se aplicam a discursos diversificados, com objetivos bem definidos e que servem para desvelar o que está oculto no conteúdo das mensagens. Absolve e cauciona o investigador por este interesse pelo escondido, o não aparentemente dito. Sendo assim, a análise de conteúdo é um método que busca desvendar o oculto nas mensagens; é, portanto, necessário colocar em evidência as inferências.

O tipo de análise de conteúdo escolhido foi o de codificação. Para Bardin (2009), a codificação é um processo pelo qual os dados do texto são transformados, transformação esta que, por recorte, agregação e enumeração, permite atingir uma representação do conteúdo ou da sua expressão. Foi trabalhado com os dados codificados em categorias.

\section{APRESENTAÇÃO E ANÁLISE DOS RESULTADOS}

Houve muitas concordâncias e respostas similares das entrevistadas devido a essas mulheres estarem vivenciando contextos semelhantes. Sendo assim, os dados foram separados em cinco categorias analíticas, Mulheres em cursos de TI, Desigualdades no mercado de trabalho e no cotidiano, Fatores socioculturais na formação de estereótipos de gênero, Carreira e o fenômeno teto de vidro, e Relações de gênero no trabalho, conforme exposto a seguir. 
A primeira categoria analisada como forma de compreender como se dá a experiência de mulheres no ambiente acadêmico em cursos de $\mathrm{TI}$ e o porquê de pouca representatividade.

Ferreira et al. (2012) afirmam que 79\% das mulheres desistem dos cursos de $\mathrm{Tl}$ e que o motivo pode não ser elas, e sim o ambiente, no qual encontram a predominância masculina. Saboya e Carvalho (2012) questionam as diferentes formas de hostilização colocadas em prática pelos colegas em relação às alunas dos cursos de TI. Ferreira et al. (2012) também dizem que o mercado de tecnologia ainda é um setor dominado pelos homens, mas que está mudando, mesmo que longe da disparidade ser ideal.

As afirmações das autoras ficam evidentes nas falas das entrevistadas sobre os cursos de tecnologia, nos quais a maioria são homens e há preconceito por parte dos alunos e até mesmo professores, conforme visto a seguir.

Na nossa turma, é bem meio a meio, são cinco meninos e quatro meninas, mas na
turma que se formou no semestre passado acho que tinha duas meninas em um
total de 15 pessoas, então não é muito padrão mesmo meninas nessa área. (RES-
PONDENTE 1).
Uma vez sofri bullying por ter tirado a melhor nota em uma prova em que $95 \%$ dos
colegas eram homens em uma disciplina da Engenharia. As piadas vieram do pró-
prio professor, que ficou gozando os alunos por terem ficado atrás de uma "mu-
Iherzinha". (RESPONDENTE 3).
Como uma das poucas mulheres da turma - de 20 pessoas, só três eram mulheres
-, sentia a necessidade de mostrar ser capaz e melhor que os colegas. Após, tudo
ficou normal, sem preconceito comigo. Mas já vi bastante preconceito acontecer
com uma colega que não tinha muito conhecimento e experiência em TI. (RES-
PONDENTE 7).
Desde que comecei a fazer cursos, não necessariamente o superior, notei que ti-
nham poucas mulheres na área; na época eu não questionava muito isso e me
acostumei. Hoje em dia, eu procuro participar de eventos que estimulam mulheres
a conhecer e ingressar na área e procuro ler sempre a respeito. Na própria empresa
onde trabalho isso é muito discutido e tem um número relativamente alto de mu-
Iheres. [...] Já fiz muitos cursos na área e, por estar acostumada com a convivência
com homens e com piadinhas machistas, por muito tempo eu achei que se não tem
muitas mulheres no mercado de TI é porque o problema somos nós. Ao longo dos
anos que fui abrindo mais a cabeça e começando a questionar tudo isso [...]. (RES-
PONDENTE 8).

A segunda categoria analisada é quanto às desigualdades e discriminações que ocorrem no trabalho e no dia a dia das empresas. Conforme visto pela literatura, a participação das mulheres no mercado de trabalho cresce progressivamente, mas as desigualdades de oportunidades, a diferenciação salarial, a divisão sexual do trabalho e o assédio moral e/ou sexual existem e nota-se que ainda são recorrentes no ambiente organizacional, como mostram os relatos:

Nas entrevistas de estágio que fiz, a prioridade era menino; eles diziam: “Ah, nós queremos um menino", mas na vaga estava normal, não informava que era só para homens, mas quando chegava na entrevista eles diziam que tinham preferência por menino. (RESPONDENTE 1).

Muito mais. Sou a única desenvolvedora na sala onde trabalho. Além disso, participei de um evento chamado Rails Girls neste final de semana, que busca a inserção de mais mulheres na área de $\mathrm{Tl}$, e foi a primeira vez que puderam obter todas as treinadoras mulheres; eu fui uma delas, pois é muito difícil encontrar mulheres na área, mesmo estando no Tecnopuc, onde há um número gigante de funcionários da 
área de TI. As empresas que possuem ações para integrar e contratar mais mulheres possuem em torno de $30 \%$ de mulheres trabalhando, imagina a porcentagem que sobra para o resto. (RESPONDENTE 10).

Daniel (2011) diz que, no cotidiano no ambiente de trabalho, as mulheres estão sujeitas a comentários preconceituosos, que reforçam essas diferenças entre gêneros e citou como exemplo relatos de mulheres de cursos da área de exatas e manutenção que constantemente ouviam "piadas" que causavam constrangimento.

Inserida em um ambiente de "piadas" e "brincadeiras" discriminatórias, há necessidade de mudança na conduta da mulher no dia a dia do trabalho. Muitas relataram terem se tornado mais sérias para evitar quaisquer assédios.

Me tornei uma pessoa mais séria e menos brincalhona para evitar os inevitáveis assédios que sofremos em todas as áreas. (RESPONDENTE 3).

No início eu era muito brincalhona e tive muito problema, um problema bem grande referente a isso, que me afetou muito; tive umas consequências bem grandes na empresa e então tive que ficar mais séria, mais chata e mais fechada com a relação com meus colegas. (RESPONDENTE 4).

Devido à quantidade de homens colegas, me tornei mais séria, sem fazer muitas brincadeiras. (RESPONDENTE 7).

Segundo uma pesquisa da World Economic Forum (2011), o Brasil é um dos piores países quando se fala em desigualdade salarial. As mulheres muitas vezes chegam a ganhar metade dos homens para exercer o mesmo cargo. Lúcio e Garcia (2016) dizem que as mulheres ocupam cargos de trabalho que pagam menores salários, alguns tipicamente femininos, porque há empregos tradicionalmente considerados masculinos e a mão e obra feminina segue muitas vezes rebaixada. É percebível que ainda ocorre desigualdade salarial e receio ou espanto por uma mulher realizar atividades de TI.

Na empresa em que trabalho com certeza não [há desigualdade salarial], mas infelizmente é uma exceção. Já conheci mulheres que receberam propostas de salários inferiores aos dos homens para o mesmo cargo e leio muitas matérias em relação às dificuldades que temos de crescer nas empresas. (RESPONDENTE 8).

Diversas vezes no início da minha carreira. Principalmente com relação aos clientes, que agendavam algum atendimento e ficavam surpresos ao receber uma mulher em vez de um homem. Já ouvi algumas vezes: "Você quem vai fazer o conserto do equipamento?" Ou então: "Tem certeza que você sabe mexer nisto?". (RESPONDENTE 3).

No meu caso, não. Mas posso falar do meu marido, que trabalha em TI também, e posso olhar mais para o trabalho dele; ele trabalha com mulheres na mesma posição, fazem o mesmo trabalho, e o salário é muito diferente. E não é em função dele ter mais cursos ou mais formação porque ele não tem, então isso é bem sacanagem. Já vi casos que a diferença é bem grande mesmo. (RESPONDENTE 4).

Sim, verifico diferença clara no salário. E nas tarefas existem diferenciações também, mas no meu caso foi para melhor. Pude escolher as tarefas mais próximas do meu perfil por ser mais comunicativa do que os outros. (RESPONDENTE 7).

No que se refere à terceira categoria, as mulheres ainda optam por campos considerados femininos, como já visto através do número da participação e desistência em cursos de exatas. Isso remete às diferenças de gêneros às quais as mulheres foram e continuam sendo submetidas historicamente e que influenciam nas escolhas e na internalização de estereótipos criados pela sociedade. Lima (2013) diz que as preferências das mulheres são por 
áreas consideradas femininas. Verificou-se, através dos relatos das respondentes, que a formação desses pressupostos imperam fortemente.

\begin{abstract}
Antigamente eram os nerds, porém acho que tem se desconstruído este estereótipo ultimamente. (RESPONDENTE 2).

Sobre preconceitos, ouço falar que as pessoas precisam ser meio nerds para entrar para a computação; são meio "bicho-grilo"; preferem interagir com as máquinas do que com as pessoas. Fora a questão que a computação não é um lugar para muIher. (RESPONDENTE 3).

Sim, parece, inclusive, algo "cultural". Parece que há algumas profissões que são de homens e outras profissões que são de mulheres. Vivi e vivo isso vendo minha mãe trabalhando como mecânica, uma profissão estereotipada como masculina. E creio que o mesmo aconteça com TI. (RESPONDENTE 6).

Acredito que seja por questões culturais que, por incrível que pareça, ainda acontecem em 2016. Desde criança somos criados e criadas sabendo que existem coisas de meninos e coisas de meninas, desde cores a brinquedos e, até mesmo, profissão. Percebo que as "coisas" de menina nunca estimulam a lógica e a criatividade, algo que está totalmente relacionado à área de exatas. Coisas de menina é sempre cuidar da sua casinha, cuidar do bebê e fazer comidinha, enquanto os meninos são estimulados a jogar videogame, brincar com lego, etc. (RESPONDENTE 8).
\end{abstract}

A sexualidade das mulheres da área de Tl também é questionada, e isso está relacionado à imagem de que o ramo da tecnologia é somente para homens. Castro (2013) explica que essa percepção, a da associação entre tecnologia e masculinidade, tem como base uma normatização de gênero bastante discutido pela literatura sociológica. Tal afirmação fica fortemente ilustrada na fala das entrevistadas.

Sempre falam alguma piada, fazem algum comentário maldoso e sempre, em qualquer lugar, piada até no trabalho, mesmo, os colegas. Piada sobre ser nerd, ou, se é mulher, é gay. (RESPONDENTE 4).

As pessoas no geral acham que tu é [sic] nerd, ou se tu é [sic] mulher e está na TI, eles já acham que tu é [sic] lésbica, isso já me falaram. O pessoal é bem preconceituoso. Tem essa ideia de que quem é da TI é uma pessoa isolada e nerd. (RESPONDENTE 1).

Acredito que o ambiente de TI ainda é muito machista, e faltam, sim, oportunidades para mulheres na área. Não só nessa área, mas sempre tive que me esforçar duas vezes mais para obter destaque e estar na mesma "posição" que os homens. Acho que toda mulher enfrenta desafios para ser respeitada, principalmente em uma profissão que conta muito com a lógica, e os homens normalmente acham que mulheres não estão aptas para isso, por mais arcaico que pareça. Não que falem isso diretamente para mim, mas é fácil de perceber através de piadas naturais no dia a dia. (RESPONDENTE 10).

As respondentes reforçam que o ambiente de Tl é muito machista e que há comentários maldosos até do que diz respeito à vida pessoal da mulher, a qual é colocada em pauta no ambiente de trabalho. É importante destacar que o preconceito não afeta todas as muIheres por igual; muitas vezes, opera de forma sutil e velada, bem como de forma explícita. Essas diferentes facetas do preconceito de gênero foram percebidas nos relatos.

A quarta categoria centra no fenômeno antigo, mas ainda presente nas dinâmicas de relações no trabalho, trata de uma barreira que, ainda que seja sutil, é suficientemente forte para impossibilitar o progresso das mulheres em níveis mais altos na hierarquia organizacional. Olinto (2011) diz que o "teto de vidro" é um tipo de segregação e faz com que as mulheres não avancem em sua carreira, inclusive nas áreas de ciência e tecnologia. Quando per- 
guntadas se já presenciaram ou vivenciaram alguma diferença ou dificuldade para assumirem cargos de comando, os relatos denotam algo que a literatura já aponta há algum tempo.

\footnotetext{
Por ser uma área predominantemente masculina em quase todas as especialidades, sinto um certo receio na contratação de mulheres para alguns cargos, principalmente os de liderança. Me parece que as oportunidades de carreira acabam se tornando menos favorecidas para as mulheres do que para os homens. (RESPONDENTE 3).

Ainda não vi mulheres chefes, só homem. Na área comercial, no RH têm, mas na área de TI ainda não vi nenhuma mulher. (RESPONDENTE 4).

Sim. No momento em que o gerente anunciou a saída do cargo, havia uma mulher e um homem concorrendo e podemos notar, pelos colegas, certo preconceito, por certos comentários, em se ter uma mulher como gerente. (RESPONDENTE 7).
}

De modo geral, pode se verificar a existência desse fenômeno no meio organizacional, embora muitas vezes ele seja "disfarçado" por um discurso de igualdade. Lima (2013) destaca que ainda há receio quanto à capacidade de liderança feminina e isso influencia a possibilidade de maior conquista em cargos de poder das organizações.

Apenas uma respondente verbaliza uma ideia contrária, como se vê a seguir. Acredita-se que ela tenha essa percepção diferente quanto a mulheres assumirem cargos de comando, uma vez que em sua empresa há forte programa de carreira:

Nossa superintendente é mulher. A maioria dos cargos de gestão de TI é ocupada por mulheres. Hoje as mulheres são gestoras das áreas de projetos, homologação, integração, SAP e Testes integrados. Existe a avaliação de gestão por competências, que avalia os colaboradores por arrastar de conhecimento e interesses. Um ponto positivo que temos é a descrição de cargos, que mapeia tudo o que os colaboradores precisam ter conhecimento/experiência para subir de cargo na companhia; acho que isso representa clareza no processo seletivo/promoções. (RESPONDENTE 2).

Pode-se concluir, com essa declaração, que as empresas que aderem a programas de carreira e/ou de Pró-Equidade baseado em práticas e fomento de relações mais igualitárias de trabalho e desempenho geram um ambiente de trabalho motivador, favorecendo a gestão e cultura da empresa.

O último aspecto analisado retoma ao estudo sobre relações de gênero, que traz como principal reflexão a desconstrução de pressupostos sexuais, tidos como justificadores de desigualdades entre homens e mulheres. Costa et al. (2012) destacam que se o gênero é a primeira maneira de significar as relações de poder, é importante compreender como essas relações acontecem e como fazem parte da construção social do masculino e feminino. Silva (2010) traz que as organizações são geridas por homens há séculos e, com o ingresso das mulheres no mundo corporativo, estes temem perder os privilégios que os fazem sentiremse superiores a elas. Quando interrogadas se dentro da área de tecnologia, quanto às relações entre colegas, havia certa dominação de poder dos homens para com as mulheres, pôde-se inferir, através das narrativas a seguir, que o cenário de dominação masculina ainda codifica os valores na sociedade e no campo organizacional de muitas empresas.

Tem. Eles sempre tendem a falar que sabem mais, que já explicou tal assunto mais de uma vez. Acham que dominam mais essa área e têm a palavra final. (RESPONDENTE 4).

Existe a tentativa disso, mas é necessário se impor, após isso o tratamento altera. (RESPONDENTE 7). 
Sim. É bastante comum mulheres não serem levadas a sério nesta profissão, nem mesmo dirigir a palavra a nós em uma reunião, por exemplo. Muitas vezes os homens impõem uma opinião e isso deixa as mulheres desconfortáveis em contestar justamente por estarem de saco cheio por esse tipo de situação ser tão comum. (RESPONDENTE 8).

Acho que os homens vão sempre se impor e achar que sua opinião prevalece, por isso é importante que nós, mulheres, saibamos impor e exigir respeito às nossas opiniões no ambiente de trabalho. Eu faço isso diariamente. (RESPONDENTE 10).

As mulheres têm que provar constantemente que são tão competentes e qualificadas quanto os homens para conseguirem seu espaço e se impor no mundo corporativo da tecnologia. Contudo, é importante concluir que é impossível compreender as relações de gênero construídas no meio organizacional sem levar em conta a cultura da empresa. Nesse sentido, pode-se compreender também que essa cultura pode servir como um reforço positivo ou não na construção dessas relações de poder.

As categorias analisadas, bem como os dados discutidos, também estão diretamente relacionadas com as questões centrais das relações de poder entre gêneros: o debate das desigualdades de gêneros, a questão da mulher em cargos de comando, a mão de obra feminina no campo da Tl e a sua atual inserção. Todos esses aspectos são tocados dentro do ambiente de trabalho. Tal articulação denota a importância de se pensar as relações de poder entre os gêneros e suas desigualdades dentro do campo organizacional.

\section{CONSIDERAÇÕES FINAIS}

Este artigo objetivou analisar o motivo da pouca representatividade feminina e a sua desistência nos cursos de TI, assim como a atual inserção, atuação e relações de poder entre gêneros no ambiente organizacional de tecnologia. Foi verificado que há um ambiente acadêmico desafiador para as mulheres nos cursos de exatas, uma vez que, por fatores socioculturais, tem-se forte ideia de que tecnologia é atividade para homem executar. A associação de que algumas habilidades e ocupações são mais "adequadas" para os homens e outras para mulheres se dá através da naturalização de habilidades sociais, que continua presente na concepção das entrevistadas, visão que é reproduzida no ambiente corporativo de TI.

Os estudos de gênero trazem importantes contribuições para os estudos de trabalho, mostrando que as mulheres são expostas a condições de trabalho diferentes daquelas encontradas por seus colegas do sexo oposto.

Além dos diversos outros obstáculos que enfrentam pelo simples fato de serem muIheres, os dados demonstram que, mesmo com a existência de alguns avanços, a mão de obra feminina segue rebaixada em relação à mão de obra masculina.

Percebe-se, a partir de então, que mesmo que já inseridas no ambiente de $\mathrm{TI}$, as muIheres passam por dificuldades em afirmar seu espaço e sua habilidade para exercer tal função.

A pesquisa ainda possibilitou identificar que o fenômeno "teto de vidro" continua presente em algumas empresas e que, dessa forma, a mulher precisa constantemente reforçar suas capacidades e habilidades para atuar em cargos de comando. Verificou-se, também, que as relações de poder entre gêneros no ambiente de $\mathrm{TI}$ acontecem com certa dominação dos homens em relação às mulheres e que elas têm a consciência de que isso é uma realidade e que precisam se impor para inverter a atual situação.

Este estudo buscou compreender algumas realidades organizacionais focando as relações de gênero. É uma tentativa de fomento ao debate da atual situação da mulher no 
mercado de trabalho em uma área dominada por homens que visa propor novas reflexões e ideias acerca de uma gestão mais igualitária entre gêneros no espaço organizacional das empresas de tecnologia da informação. Sendo esta pesquisa uma amostra intencional, realizado apenas com mulheres, não se pode generalizar as respostas, sendo esse um dos fatores de limitações da pesquisa, assim como o fator do tamanho da amostra, que ao se apresentar em número reduzido, permite considerar os resultados apenas para a população em questão. Como sugestão para outros trabalhos, um complemento a este estudo seria analisar o ponto de vista dos homens da área de TI quanto à atuação das mulheres nesta área e a dinâmica das relações de poder entre gêneros.

É essencial que haja um compromisso de seus dirigentes para que o valor seja assumido e, assim, as práticas da diversidade e a inclusão de minorias sejam feitas. Pode-se afirmar que o mundo corporativo tende a reproduzir as injustiças que existem na própria sociedade, não estando livre de repetir e também fomentar tais desigualdades.

\section{REFERÊNCIAS}

ALENCAR, W. C. Os direitos humanos no mundo do trabalho: raça e gênero nas organizações - um olhar sobre nós mesmos. Cadernos Zygmunt Bauman, Maranhão, v. 5, n. 10, 2015.

ALMEIDA, P. P. Essa empresa não é lugar de mulher parideira: considerações feministas sobre as relações de gênero nas organizações. 2012.

ALVES, M; GALEÃO-SILVA, L. A crítica da gestão da diversidade nas organizações. Revista de Administração de Empresas, v. 44, n. 3, 2004.

APINFO. Pesquisa, 2012. Disponível em: http://www.apinfo.com/p12sexo-idade.html. Acesso em: 10 abr. 2016.

BARBOSA, R. C., CARVALHO, M. E. P., FERNANDES, M. O. M. Gênero e Tecnologias da Informação: um olhar sobre a Educação Superior na Paraíba e as possibilidades de promoção da equidade de gênero através da Educação. In: MONTANÉ LÓPEZ, A.; CARVALHO, M. E. P. (Coord). Mujeres y educación superior. João Pessoa: Editora da UFPB, 2013.

BARDIN, L. Análise de conteúdo. Lisboa: Edições 70, 2009.

BASTOS, C.; KELLER, V. Aprendendo a aprender: introdução à metodologia científica. Petrópolis: Vozes, 2000.

BEAUVOIR, S. O segundo sexo: a experiência vivida. São Paulo: Difusão Européia do Livro, 1975.

BRASIL. Ministério da Educação e Cultura. Catálogo Nacional dos Cursos Superiores de Tecnologia. Brasília: MEC, 2010. 141p. Disponível em:

http://portal.mec.gov.br/index.php?option=com docman\&view=download\&alias=7237catalogo-nacioanl-cursos-superiores-tecnologia-2010\&category slug=dezembro-2010pdf\&ltemid=30192. Acesso em: 10 fev.2019. 
CASTRO, B. G. Afogados em contratos: o impacto da flexibilização do trabalho nas trajetórias dos profissionais de TI. 2013. Tese (Doutorado em Ciências Sociais) - Universidade Estadual de Campinas, Campinas, 2013.

CERVO, A.; SILVA, R.; BERVIAN, P. A. Metodologia científica. 3. ed. São Paulo: Pearson Education, 2006.

COELHO, M. F. Feminismo, gênero e violência contra a mulher: uma análise da produção teórica. 99 f. Monografia (Bacharel em Serviço Social) - Universidade de Brasília. 2014.

COOPER, J. et al. Improving gender equity in postsecondary education. In: KLEIN, S. S. (Ed.). Handbook for achieving gender equity through education. New York: Routledge, 2010.

COSTA, R. G.; SILVEIRA, C. M. H.; MADEIRA, M. Z. A. Relações de gênero e poder: tecendo caminhos para a desconstrução da subordinação feminina. In: ENCONTRO NACIONAL DA REDE FEMINISTA NORTE E NORDESTE DE ESTUDOS E PESQUISA SOBRE A MULHER E RELAÇÕES DE GÊNERO, 17., João Pessoa, 2012. Anais [...] João Pessoa: CEDU/UFPB, 2012.

DANIEL, C. O trabalho e a questão de gênero: a participação de mulheres na dinâmica do trabalho. O social em questão, Rio de Janeiro, ano XIV, n. 25/26, 2011.

FERREIRA, J. C.; SANTOS, S. A. S.; TOMÉ, M. F. Mulher e mercado de trabalho: uma revisão sobre os percursos da mulher no mercado do trabalho. Revista Faculdade de Ensino Superior e Formação Integral, Garça, v. 20, jun. 2012.

FRANÇA, L. Mudança à Vista. VOCÊ S/A, São Paulo, edição 153, p. 56-57, março, 2011.

GARCIA, L. S.; CONFORTO, E. A inserção feminina no mercado de trabalho urbano brasileiro e renda familiar. Disponível em: http://cdn.fee.tche.br/jornadas/2/H7-03.pdf. Acesso em: 9 abr. 2016.

GODOY, A. S. Introdução à pesquisa qualitativa e suas possibilidades. Revista de Administração de Empresas, São Paulo, v. 35, n. 2, p. 57-63, mar./abr. 1995.

GONÇALVES, H. A. Manual de metodologia da pesquisa científica. 2. ed. São Paulo: Avercamp, 2014.

INSTITUTO NACIONAL DE ESTUDOS E PESQUISAS EDUCACIONAIS ANÍSIO TEIXEIRA (INEP). Relatório Censo da Educação Superior 2013. Brasília, DF: INEP, 2013.

LIMA, M. P. As mulheres na Ciência da Computação. Estudos Feministas, Santa Catarina, v. 21, n. 3, p. 793-816, set.-dez. 2013.

LÚCIO, C. G.; GARCIA, M. D. Desafios para a igualdade no mercado de trabalho. Brasileiros, São Paulo, 2016. 
MADALOZZO, R. CEOs e composição do conselho de administração: a falta de identificação pode ser motivo para existência de teto de vidro para mulheres no Brasil? Revista de Administração Contemporânea, Curitiba, v. 15, n. 1, art. 7, jan/fev, 2011.

MARCONI, M. A.; LAKATOS, E. M. Técnicas de pesquisa. 5. ed. São Paulo: Atlas S.A, 2002.

MINAYO, M. C. de S. Pesquisa Social: teoria, método e criatividade. 2. ed. Petrópolis: Vozes, 1994.

MOREIRA, J. A.; MATTOS, G. O.; REIS, L. S. Um panorama da presença feminina na Ciência da Computação. In: REDE FEMINISTA NORTE E NORDESTE DE ESTUDOS E PESQUISA SOBRE A MULHER E RELAÇÕES DE GÊNERO, 18., Recife, 2014. Anais [...] Recife, 2014.

MORESI, E. Metodologia da pesquisa. Brasília, DF: UCB, 2003. Disponível em:

http://www.inf.ufes.br/ pdcosta/ensino/2010-2-metodologia-de-

pesquisa/MetodologiaPesquisa-Moresi2003.pdf. Acesso em: 5 jun. 2016.

OLINTO, G. A inclusão das mulheres nas carreiras de ciência e tecnologia no Brasil. Inclusão Social, Brasília, 2011. Disponível em: http://revista.ibict.br/inclusao/article/view/1667/1873. Acesso em: 14 abr. 2016.

PINTO, É. J. S.; CARVALHO, M. E. P.; RABAY, G. Gênero: um fator condicionante nas escolhas de cursos superiores. In: REDOR, 18., Recife, 2014. Anais [...] Recife: UFRPE, 2014. Disponível em: https://paradoxzero.com/zero/redor/wp-content/uploads/2015/04/1893-4523-1-

PB.pdf. Acesso em: 5 jun. 2016.

PORTAL BRASIL. Mulheres são maioria da população e ocupam mais espaço no mercado de trabalho. Disponível em: http://www.brasil.gov.br/cidadania-e-justica/2015/03/mulheressao-maioria-da-populacao-e-ocupam-mais-espaco-no-mercado-de-trabalho. Acesso em: 9 abr. 2016.

PRÊMIO WEPs BRASIL. Disponível em: http://premiowepsbrasil.org/. Acesso em: 14 abr. 2016.

QUEIROZ, C. T. A. P.; CARVALHO, M. E. P.; MOREIRA, J. A. Gênero e inclusão de jovens muIheres nas ciências exatas, nas engenharias e na computação. In: REDOR, 18., Recife, 2014. Anais [...] Recife: UFRPE, 2014. Disponível em: http://paradoxzero.com/zero/redor/wpcontent/uploads/2015/07/2076-4738-1-PB.pdf. Acesso em: 12 abr. 2016.

RAMOS, M. O. Mulheres no mercado de trabalho. Revista científica integrada, Ribeirão Preto, v. 1, n. 4. 2011

REZENDE, D. T. Formação e qualificação profissional e atuação feminina nas áreas de tecnologia da informação (TI). 2014. Disponível em:

http://www.educacao.cefetmg.br/galerias/arquivos download/GT08a.pdf. Acesso em: 12 abr. 2016. 
ROCHA, A. C. et al. A evolução dos direitos trabalhista da mulher ao longo dos tempos. Cadernos de Graduação: Ciências Humanas e Sociais, Aracaju, v. 1, n. 17, 2013.

SABOYA, M. C. L.; CARVALHO, M. P. Diferenças e desigualdades na escola. Campinas: Papirus, 2012.

SABOYA, M. C. L. Relações de gênero, ciência e tecnologia: uma revisão da bibliografia nacional e internacional. Educação, Gestão e Sociedade: revista da Faculdade Eça de Queirós, ano 3, n. 12, nov. 2013. Disponível em:

http://uniesp.edu.br/sites/ biblioteca/revistas/20170509155548.pdf. Acesso: 12 abr. 2016.

SILVA, S. M. Mulheres e feminilidade em culturas ocupacionais de hegemonia masculina. Lisboa: CITE. 2010.

SIMÕES, F. I. W. Mulher, mercado de trabalho e as configurações familiares do século XX. Revista Vozes dos Vales da UFVJM, Minas Gerais, anos 1, n. 2, out. 2012.

SORANZ, D. Políticas de Saúde para a cidade do Rio de Janeiro: o desafio da mudança do modelo de atenção. 2010.

VAZ, D. V. O teto de vidro nas organizações públicas: evidências para o Brasil. Economia e Sociedade, Campinas, v. 22, n. 3, p. 765-790, 2013. Disponível em:

https://periodicos.sbu.unicamp.br/ojs/index.php/ecos/article/view/8642183/9665. Acesso em: 12 abr. 2016.

WORD ECONOMIC FORUM, 2011. Disponível em:

http://www.observatoriodegenero.gov.br/menu/noticias/brasil-ocupa-82a-posicao-emranking-de-desigualdade-entre-mulheres-e-homens/image/image view fullscreen. Acesso em: 10 fev. 2019 . 